This copy is for your personal, non-commercial use only.

If you wish to distribute this article to others, you can order high-quality copies for your colleagues, clients, or customers by clicking here.

Permission to republish or repurpose articles or portions of articles can be obtained by following the guidelines here.

The following resources related to this article are available online at www.sciencemag.org (this information is current as of June 25, 2012 ):

Updated information and services, including high-resolution figures, can be found in the online version of this article at:

http://www.sciencemag.org/content/306/5695/499.full.html

Supporting Online Material can be found at:

http://www.sciencemag.org/content/suppl/2004/10/13/306.5695.499.DC1.html

A list of selected additional articles on the Science Web sites related to this article can be found at:

http://www.sciencemag.org/content/306/5695/499.full.html\#related

This article has been cited by 128 article(s) on the ISI Web of Science

This article has been cited by 28 articles hosted by HighWire Press; see:

http://www.sciencemag.org/content/306/5695/499.full.html\#related-urls

This article appears in the following subject collections:

Psychology

http://www.sciencemag.org/cgi/collection/psychology 
study also provides a window into how the possibly innate distinction (26) between quantifying small versus large sets of objects is relatively unelaborated in a life without number words to capture those exact magnitudes (32).

\section{References and Notes}

1. S. C. Levinson, J. Linguist. Anthropol. 7, 98 (1997).

2. P. Li, L. Gleitman, Cognition 3, 83 (2002).

3. S. C. Levinson, S. Kita, D. B. M. Haun, B. H. Rasch, Cognition 4, 84 (2002).

4. J. A. Lucy, Grammatical Categories and Cognition. (Cambridge Univ. Press, Cambridge, 1992).

5. R. W. Brown, E. H. Lenneberg, J. Abnorm. Soc. Psychol. 49, 454 (1954).

6. K. Menninger, Number Words and Number Symbols: A Cultural History of Numbers (MIT Press, Cambridge, MA, 1969).

7. C. Zaslavsky, Africa Counts: Number and Pattern in African Culture (Prindle, Weber, and Schmidt, Boston, 1973).

8. R. Gelman, C. R. Gallistel, The Child's Understanding of Number (Harvard Univ. Press, Cambridge, MA, 1978).

9. Materials and methods are available as supporting material on Science Online.

10. S. Carey, Mind Lang. 16, 37 (2001).

11. L. Feigenson, S. Carey, M. Hauser, Psychol. Sci. 13, 150 (2002).
12. B. J. Scholl, Cognition 80, 1 (2001).

13. T. J. Simon, Cognit. Dev. 12, 349 (1997).

14. L. Trick, Z. W. Pylyshyn, Psychol. Rev. 101, 80 (1994).

15. C. Uller, G. Huntley-Fenner, S. Carey, L. Klatt, Cognit. Dev. 14, 1 (1999).

16. F. Xu, Cognition 89, B15 (2003).

17. P. Gordon, paper presented at the biennial meeting of the Society for Research in Child Development, New Orleans, LA, 25 to 28 March 1993.

18. P. Gordon, paper presented at the European Society for Philosophy and Psychology, Paris, France, 1 to 4 September 1994.

19. W. H. Meck, R. M. Church, J. Exp. Psychol. Anim. Behav. Processes 9, 320 (1983).

20. H. Barth, N. Kanwisher, E. Spelke, Cognition 86, 201 (2003).

21. S. Cordes, R. Gelman, C. R. Gallistel, J. Whalen, Psychon. Bull. Rev. 8, 698 (2001)

22. C. R. Gallistel, The Organization of Learning (MIT Press, Cambridge, MA, 1990).

23. J. Whalen, C. R. Gallistel, R. Gelman, Psychol. Sci. 10, 130 (1999).

24. S. Cordes, R. Gelman, C. R. Gallistel, J. Whalen, Psychon. Bull. Rev. 8, 698 (2001).

25. S. Dehaene, The Number Sense (Oxford Univ. Press, New York, 1997).

26. B. Butterworth, What Counts (Simon \& Schuster New York, 1999).

27. J. S. Lipton, E. S. Spelke, Psychol. Sci. 14, 396 (2003).

28. M. D. Hauser, F. Tsao, P. Garcia, E. S. Spelke, Proc. $R$ Soc. London B 270, 1441 (2003).
29. S. Dehaene, E. Spelke, P. Pinel, R. Stanescu, S. Tsivkin, Science 284, 970 (1999).

30. J. R. Platt, D. M. Johnson, Learn. Motiv. 2, 386 (1971)

31. Cordes et al. (24) suggest that analog representations exist even for $n=2$, because subjects made errors on a task in which counting was suppressed during rapid button pressing. However, errors in this range also occurred when subjects counted and might have been the result of perseveration errors rather than reflecting numerical representations.

32. One can safely rule out that the Pirahã are mentally retarded. Their hunting, spatial, categorization, and linguistic skills are remarkable, and they show no clinical signs of retardation.

33. I thank D. Everett and K. Everett for making this research possible; SIL in Porto Velho and E. Ramos for logistical support; and S. Carey, L. Feigenson, D. Everett, C. Tamis-LeMonda, M. Miozzo, G. Marcus, $\mathrm{F}$. Xu, and K. Adolph for comments on the paper.

Supporting Online Material

www.sciencemag.org/cgi/content/full/1094492/DC1

Methods

SOM Text

Figs. S1 to S3

Movies S1 and S2

References

9 December 2003; accepted 29 July 2004

Published online 19 August 2004;

$10.1126 /$ science. 1094492

Include this information when citing this paper.

\title{
Exact and Approximate Arithmetic in an Amazonian Indigene Group
}

\author{
Pierre Pica, ${ }^{1}$ Cathy Lemer, ${ }^{2}$ Véronique Izard, ${ }^{2}$ Stanislas Dehaene ${ }^{2 *}$
}

Is calculation possible without language? Or is the human ability for arithmetic dependent on the language faculty? To clarify the relation between language and arithmetic, we studied numerical cognition in speakers of Mundurukú, an Amazonian language with a very small lexicon of number words. Although the Mundurukú lack words for numbers beyond 5, they are able to compare and add large approximate numbers that are far beyond their naming range. However, they fail in exact arithmetic with numbers larger than 4 or 5 . Our results imply a distinction between a nonverbal system of number approximation and a language-based counting system for exact number and arithmetic.

\begin{abstract}
All science requires mathematics. The knowledge of mathematical things is almost innate in us.... This is the easiest of sciences, a fact which is obvious in that no one's brain rejects it; for laymen and people who are utterly illiterate know how to count and reckon.
\end{abstract}

Roger Bacon (1214-1294), English philosopher and scientist

\footnotetext{
${ }^{1}$ Unité Mixte de Recherche 7023 "Formal Structures of Language," CNRS and Paris VIII University, Paris, France. ${ }^{2}$ Unité INSERM 562 "Cognitive Neuroimaging," Service Hospitalier Frédéric Joliot, CEA/DSV, 91401 Orsay Cedex, France.

*To whom correspondence should be addressed. E-mail: dehaene@shfj.cea.fr
}

Where does arithmetic come from? For some theorists, the origins of human competence in arithmetic lie in the recursive character of the language faculty (1). Chomsky, for instance, stated that "we might think of the human number faculty as essentially an 'abstraction' from human language, preserving the mechanisms of discrete infinity and eliminating the other special features of language" (2). Other theorists believe that language is not essential - that humans, like many animals, have a nonverbal "number sense" (3), an evolutionarily ancient capacity to process approximate numbers without symbols or language (4-6) that provides the conceptual foundation of arithmetic. A third class of theories, while acknowledging the existence of nonverbal representations of numbers, postulates that arithmetic competence is deeply transformed once children acquire a system of number symbols (7-9). Language would play an essential role in linking up the various nonverbal representations to create a concept of large exact number (10-12).

To elucidate the relations between language and arithmetic, it is necessary to study numerical competence in situations in which the language of numbers is either absent or reduced. In many animal species, as well as in young infants before they acquire number words, behavioral and neurophysiological experiments have revealed the rudiments of arithmetic (6, 13-16). Infants and animals appear to represent only the first three numbers exactly. Beyond this range, they can approximate "numerosity," with a fuzziness that increases linearly with the size of the numbers involved (Weber's law). This finding and the results of other neuroimaging and neuropsychological experiments have yielded a tentative reconciliation of the above theories: Exact arithmetic would require language, whereas approximation would not $(12,17-21)$. This conclusion, however, has been challenged by a few case studies of adult brainlesioned or autistic patients in whom language dysfunction did not abolish exact arithmetic; such a finding suggests that in some rare cases, even complex calculation may be performed without words (22).

In the final analysis, the debate cannot be settled by studying people who are raised in a culture teeming with spoken and written symbols for numbers. What is needed is a language deprivation experiment, in which neurologically normal adults would be raised 


\section{R E P O R T S}

without number words or symbols. Although such an experiment is ethically impossible in our Western culture, some languages are intrinsically limited in their ability to express number, sometimes using a very narrow set of number words ("one, two, many") (23). These often endangered languages present a rare opportunity to establish the extent and limits of nonverbal arithmetic abilities.

Here, we studied numerical cognition in native speakers of Mundurukú, a language that has number words only for the numbers 1 through $5(24,25)$. Mundurukú is a language of the Tupi family, spoken by about 7000 people living in an autonomous territory in the Pará state of Brazil (Fig. 1). Following regular research stays since 1998, and two pilot studies in 2001 and 2002, one of us (P.P.) traveled through several villages during 2003 and was able to collect data from 55 speakers of Mundurukú in a computerized battery of numerical tests. Ten native speakers of French (mean age 50) served as controls.

The Mundurukú have some contact with nonindigenous culture and individuals, mainly through government institutions and missionaries. Thus, several of them speak some Portuguese, and a few, especially the children, receive some instruction in basic school topics (26). To evaluate the potential impact of these variables, we formed two groups of strictly monolingual adults and children without instruction, and we compared their performance with that of more bilingual and

Fig. 1. Location of indigene territories of Brazil (top) and of the main Mundurukú territory where our research was conducted (bottom). Colored dots indicate the villages where participants were tested. The legend at bottom gives the sizes of the six groups of participants and their average age. [Maps adapted with permission from R. Beto, Ed., Povos indígenas no Brasil (Instituto Socioambiental, São Paulo, Brazil, 2000), pp. 161, 461].

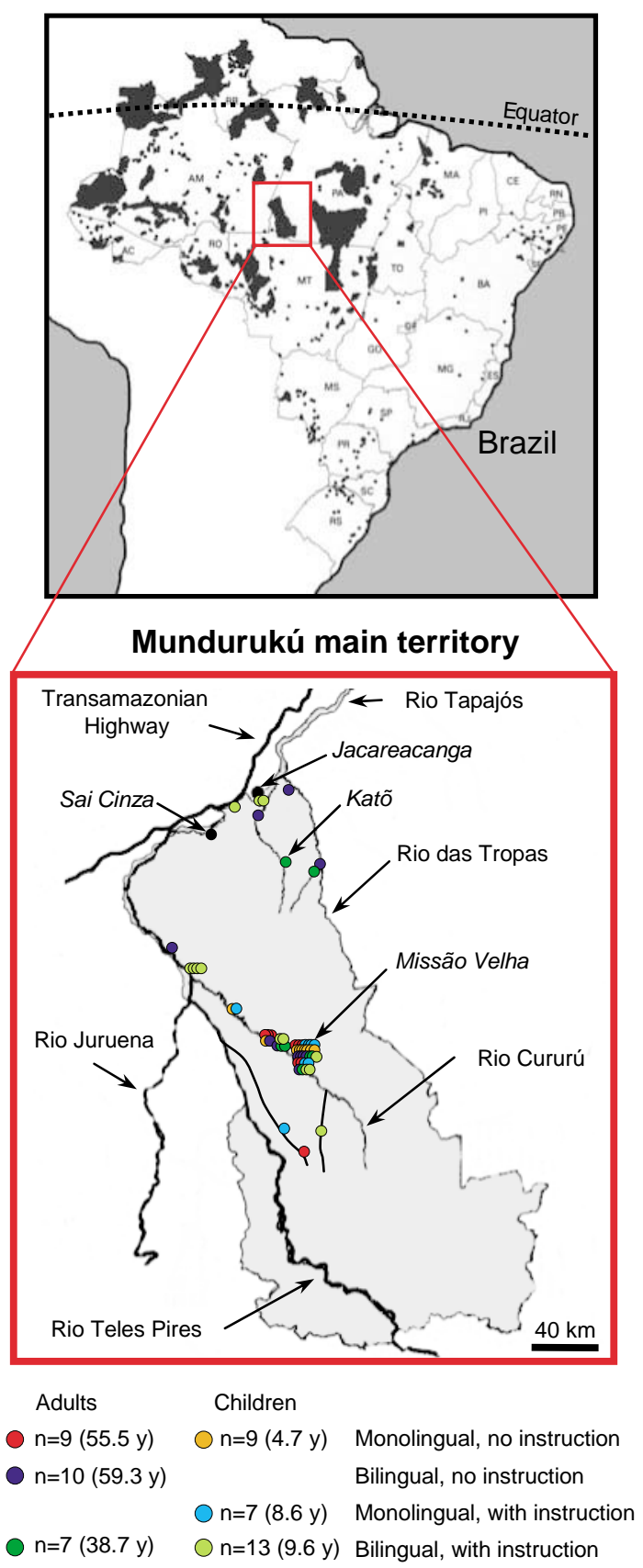

educated participants (Fig. 1). Using a solarpowered laptop computer, we collected a large amount of trials in classical arithmetical tasks, including a chronometric comparison test. This allowed us to test whether competence for numbers is present in the absence of a well-developed language for number.

A first task explored the verbal expressions for numbers in Mundurukú (26). Participants were presented with displays of 1 to 15 dots in randomized order, and were asked in their native language to say how many dots were present. This task permitted an objective analysis of the conditions of use of number words. No systematic variation across groups was identified, except for lack of use of the word for " 5 " in the younger children, and the results were therefore pooled across all groups (Fig. 2). The results confirm that Mundurukú has frozen expressions only for numbers 1 to 5 . These expressions are long, often having as many syllables as the corresponding quantity. The words for 3 and 4 are polymorphemic: ebapũg $=2+1$, ebadipdip $=2+1+1$, where "eba" means "your (two) arms." This possibly reflects an earlier base-2 system common in Tupi languages, but the system is not productive in Mundurukú (expressions such as "eba eba dip" or "eba eba ebapũg" are not used and are judged meaningless).

Above 5, there was little consistency in language use, with no word or expression representing more than $30 \%$ of productions to a given target number. Participants relied on approximate quantifiers such as "some" (adesũ), "many" (ade), or "a small quantity" (bũrũmaku). They also used a broad variety of expressions varying in attempted precision, such as "more than one hand," "two hands," "some toes," all the way up to long phrases such as "all the fingers of the hands and then some more" (in response to 13 dots).

The Mundurukú did not use their numerals in a counting sequence, nor to refer to precise quantities. They usually uttered a numeral without counting, although (if asked to do so) some of them could count very slowly and nonverbally by matching their fingers and toes to the set of dots. Our measures confirm that they selected their verbal response on the basis of an apprehension of approximate number rather than on an exact count. With the exception of the words for 1 and 2, all numerals were used in relation to a range of approximate quantities rather than to a precise number (Fig. 2). For instance, the word for 5, which can be translated as "one hand" or "a handful," was used for 5 but also $6,7,8$, or 9 dots. Conversely, when five dots were presented, the word for 5 was uttered on only $28 \%$ of trials, whereas the words for 4 and "few" were each used on about $15 \%$ of trials. This response pattern is comparable to the use of 
round numbers in Western languages, for instance when we say "10 people" when there are actually 8 or 12 . We also noted the occasional use of two-word constructions (e.g., "two-three seeds"), analogous to references to approximate quantities in Western languages (27). Thus, the Mundurukú are different from us only in failing to count and in allowing approximate use of number words in the range 3 to 5 , where Western numerals usually refer to precise quantities.

If the Mundurukú have a sense of approximate number, they should succeed in approximation tasks with quantities beyond the range for which they have number words. If, however, concepts of numbers emerge only when number words are available, then the Mundurukú would be expected to experience severe difficulties with large numbers. We tested this alternative with the use of two estimation tasks. First, we probed number comparison. Participants were presented with two sets of 20 to 80 dots, controlled for various non-numerical variables (26), and were asked to point to the more numerous set (Fig. 3A). Mundurukú participants responded far above chance level in all groups (the minimum was $70.5 \%$ correct in the youngest group; all $P<$ $0.0001)$. There was no significant difference among the six Mundurukú groups $\left(F_{5,46}=\right.$ $1.50, P>0.20$ ), which suggests that the small level of bilingualism and instruction achieved by some of the participants did not modify performance. However, average Mundurukú performance was slightly worse than the French controls, thus creating a difference between groups $\left(F_{6,55}=2.58, P<0.028\right)$, perhaps due to distraction in some Mundurukú participants (this was the first test that they took).

In literate cultures, number comparison performance is subject to a distance effect: Performance improves as the ratio between the numbers to be compared increases, whether the targets are presented as sets of objects or symbolically as Arabic digits $(28,29)$. This classical distance effect was also observed in Mundurukú participants: Performance decreased as the ratio varied from 2 to 1.5 , 1.3 , or $1.2\left(F_{3,138}=43.2, P<0.0001\right)$. This effect was identical in all groups, including the French controls (group $\times$ distance interaction, $F<1$; see Fig. 3A). Response times were also faster for more distant numbers, in both Mundurukú $\left(F_{3,90}=12.9\right.$, $P<0.0001)$ and French participants $\left(F_{3,26}=\right.$ 4.93, $P<0.008)$. Again, although the French controls were globally faster, thus creating a main effect of group $\left(F_{6,37}=4.59, P<\right.$ $0.002)$, the distance effect was parallel in all groups (interaction $F<1$ ). Fitting the performance curve suggested that the Weber fraction, which quantifies the amount of imprecision in number representation (16), was 0.17 in Mundurukú, only marginally larger than the value of 0.12 observed in the controls. Thus, the Mundurukú clearly can represent large numbers and understand the concept of relative magnitude (30).

We then investigated whether the Mundurukú can perform approximate operations with large numbers. We used a nonsymbolic version of the approximate addition task, which is thought to be independent of language in Western participants $(12,17,18)$. Participants were presented with simple animations illustrating a physical addition of two large sets of dots into a can (Fig. 3B). They had to approximate the result and compare it to a third set. All groups of participants, including monolingual adults and children, performed considerably above chance (minimum $80.7 \%$ correct, $P<0.0001)$. Performance was again solely affected by distance $\left(F_{3,152}=78.2, P<\right.$ $0.0001)$; there was no difference between groups, nor a group $\times$ distance interaction (31). If anything, performance was higher in this addition + comparison task than in the previous comparison task, perhaps because the operation was represented more concretely by object movement and occlusion. In brief, Mundurukú participants had no difficulty in adding and comparing approximate numbers, with a precision identical to that of the French controls.

Finally, we investigated whether the Mundurukú can manipulate exact numbers. The number sense view predicts that in the absence of spoken or written symbols, number

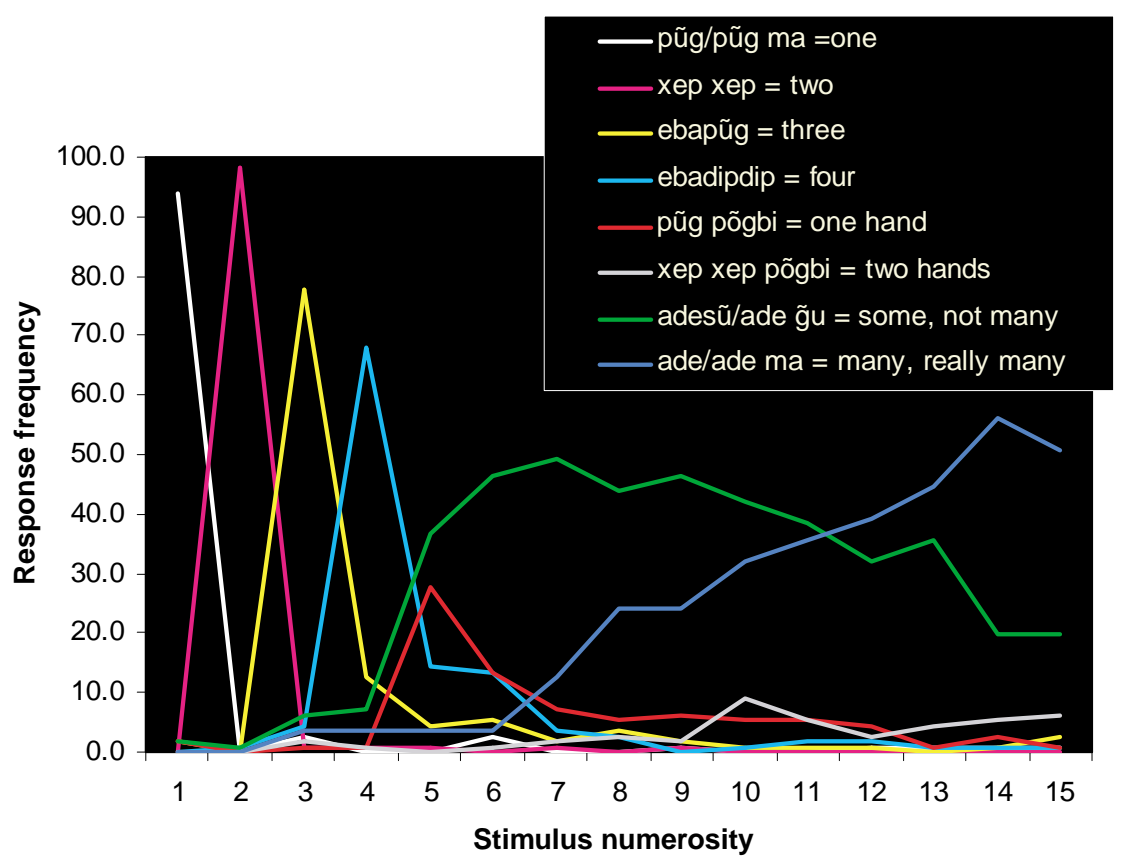

Fig. 2. Number naming in Mundurukú. Participants were shown sets of 1 to 15 dots in random order and were asked to name the quantity. For each quantity on the $x$ axis, the graph shows the fraction of times that it was named with a given word or locution. We only present the data for words or locutions produced on more than $2.5 \%$ of all trials. For numbers above 5 , frequencies do not add up to $100 \%$, because many participants produced rare or idiosyncratic locutions or phrases such as "all of my toes" (a complete list is available from the authors).

can only be represented approximately, with an internal uncertainty that increases with number (Weber's law). Beyond the range of 3 or 4 , this system cannot reliably distinguish an exact number $n$ from its successor $n+1$. Thus, the Mundurukú should fail with tasks that require manipulation of exact numbers such as "exactly six." To assess this predicted limitation of Mundurukú arithmetic, we used an exact subtraction task. Participants were asked to predict the outcome of a subtraction of a set of dots from an initial set comprising one to eight items (Fig. 3, C and D). The result was always small enough to be named, but the operands could be larger (e.g., 6-4). In the main experiment, for which we report statistics below, participants responded by pointing to the correct result among three alternatives $(0,1$, or 2 objects left). The results were also replicated in a second version in which participants named the subtraction result aloud (Fig. 3D).

In both tasks, we observed a fast decrease of performance with the size of the initial number $\left(F_{7,336}=44.9, P<0.0001\right)$. This decrease was significant in all Mundurukú groups, although a significant group effect $\left(F_{5,48}=3.81, P=0.005\right)$ and a marginal group $\times$ size interaction $\left(F_{35,336}=1.40, P=\right.$ $0.07)$ indicated that performance was slightly better in the more bilingual and educated group, especially when fewer than five dots were present (see Fig. 3D). However, all Mundurukú groups performed much worse 
A Comparison

Indicate the larger set

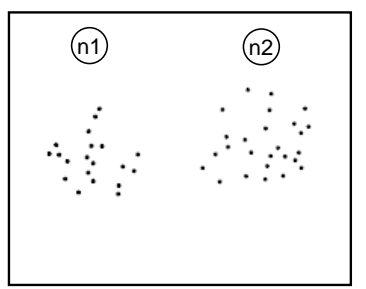

B Approximate addition and comparison

Indicate which is larger: $n 1+n 2$ or $n 3$

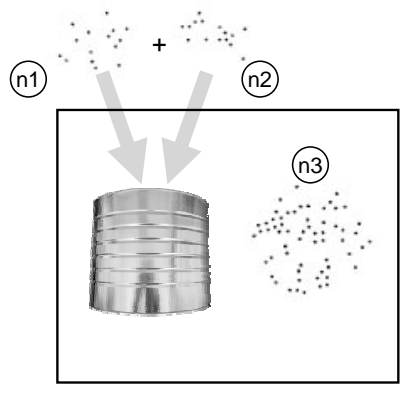

C Exact subtraction

Point to the result of $n 1-n 2$

. :

(ni1):

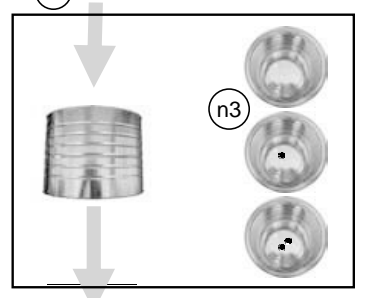

(n2) -

$\ddots$.

\section{Exact subtraction}

Name the result of $n 1-n 2$

$\because$

(11):

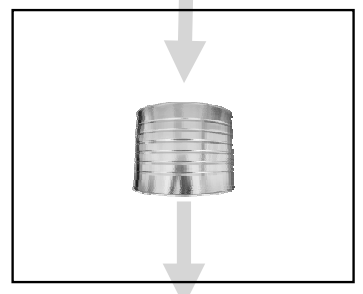

(n2).
Performance (\% correct)
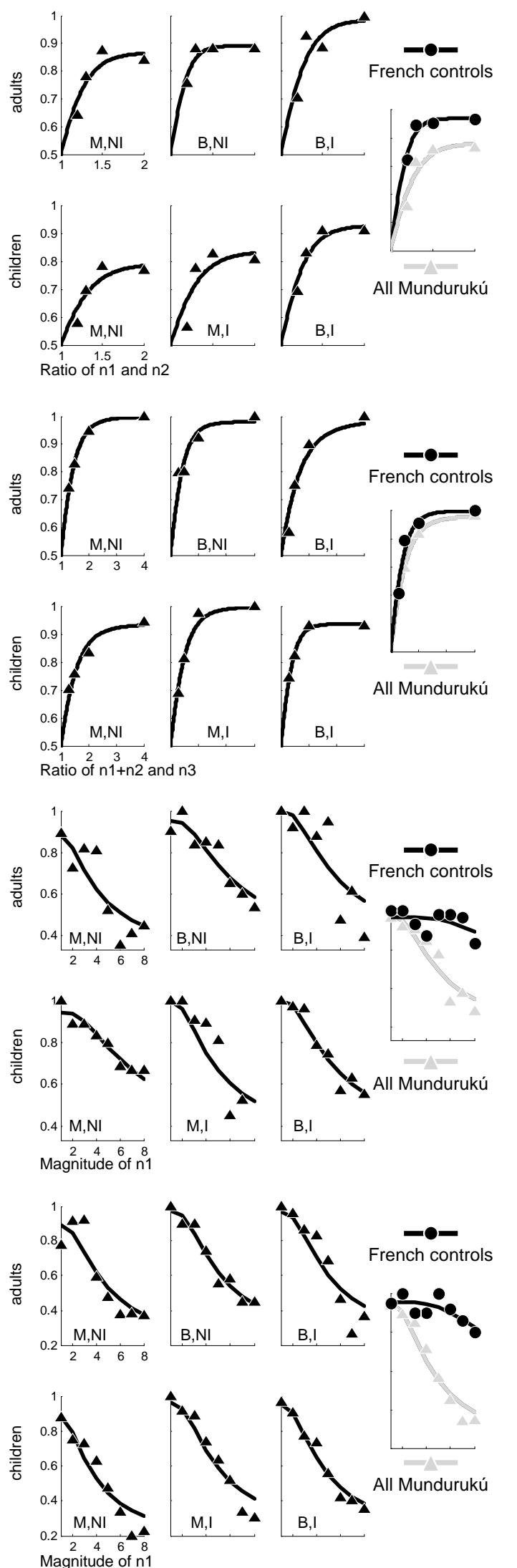

Fig. 3. Performance in four tasks of elementary arithmetic. In each case, the left column illustrates a sample trial (see movie S1). The graphs at right show the fraction of correct trials, in each group separately $(M$, monolinguals; $\mathrm{B}$, bilinguals; $\mathrm{NI}$, no instruction; I, instruction) as well as averaged across all the Mundurukú and French participants (right graphs). The lowest level on the scale always corresponds to chance performance. For number comparison ( $A$ and $B$ ), the relevant variable that determines performance is the distance between the numbers, as measured by the ratio of the larger to the smaller number (e.g. $n 1 / n 2$ if $n 1>n 2, n 2 / n 1$ otherwise). For exact subtraction ( $C$ and $D$ ), the relevant variable is the size of the initial number $\mathrm{n} 1$. The fits are based on mathematical equations described in (26).

than the French controls, in whom performance was only slightly affected by number size $\left(F_{7,63}=2.36, P<0.033\right)$. Thus, we observed a highly significant effect of language group (French versus Mundurukú, $\left.F_{1,62}=25.7, P<0.0001\right)$ and a language $\times$ size interaction $\left(F_{7,434}=6.80, P<0.0001\right)$.

The Mundurukú's failure in exact subtraction was not due to misunderstanding of the instructions, because they performed better than chance (indeed, close to $100 \%$ correct) when the initial number was below 4 . Success within this range might reflect exact verbal coding, or it might reflect a nonverbal parallel individuation of small sets, as also found in preverbal infants (13) and nonhuman primates (14). Performance also remained above chance for higher values of the initial number (e.g., $49.6 \%$ correct for $8-n$ problems, chance $=33.3 \%, P<0.0001)$. The entire performance curve over the range 1 to 8 could be fitted by a simple psychophysical equation that supposes an approximate Gaussian encoding of the initial and subtracted quantities, followed by subtraction of those internal magnitudes and classification of the fuzzy outcome into the required response categories $(0,1$, or 2$)$. Thus, the Mundurukú still deployed approximate representations, subject to Weber's law, in a task that the French controls easily resolved by exact calculation.

Together, our results shed some light on the issue of the relation between language and arithmetic. They suggest that a basic distinction must be introduced between approximate and exact mental representations of number, as also suggested by earlier behavioral and brainimaging evidence $(12,18)$ and by recent research in another Amazon group, the Pirahã (23). With approximate quantities, the Mundurukú do not behave qualitatively differently from the French controls. They can mentally represent very large numbers of up to 80 dots, far beyond their naming range, and do not confuse number with other variables such as size and density. They also spontaneously apply concepts of addition, subtraction, 
and comparison to these approximate representations. This is true even for monolingual adults and young children who never learned any formal arithmetic. These data add to previous evidence that numerical approximation is a basic competence, independent of language, and available even to preverbal infants and many animal species $(6,13-16)$. We conclude that sophisticated numerical competence can be present in the absence of a well-developed lexicon of number words. This provides an important qualification of Gordon's (23) version of Whorf's hypothesis according to which the lexicon of number words drastically limits the ability to entertain abstract number concepts.

What the Mundurukú appear to lack, however, is a procedure for fast apprehension of exact numbers beyond 3 or 4 . Our results thus support the hypothesis that language plays a special role in the emergence of exact arithmetic during child development (9-11). What is the mechanism for this developmental change? It is noteworthy that the Mundurukú have number names up to 5 , and yet use them approximately in naming. Thus, the availability of number names, in itself, may not suffice to promote a mental representation of exact number. More crucial, perhaps, is that the Mundurukú do not have a counting routine. Although some have a rudimentary ability to count on their fingers, it is rarely used. By requiring an exact one-to-one pairing of objects with the sequence of numerals, counting may promote a conceptual integration of approximate number representations, discrete object representations, and the verbal code $(10,11)$. Around the age of 3 , Western children exhibit an abrupt change in number processing as they suddenly realize that each count word refers to a precise quantity (9). This "crystallization" of discrete numbers out of an initially approximate continuum of numerical magnitudes does not seem to occur in the Mundurukú.

References and Notes

1. J. R. Hurford, Language and Number (Blackwell, Oxford, 1987).

2. N. Chomsky, Language and the Problems of Knowledge (MIT Press, Cambridge, MA, 1988), p. 169.

3. S. Dehaene, The Number Sense (Oxford Univ. Press, New York, 1997).

4. C. R. Gallistel, R. Gelman, Cognition 44, 43 (1992).

5. S. Dehaene, G. Dehaene-Lambertz, L. Cohen, Trends Neurosci. 21, 355 (1998)

6. L. Feigenson, S. Dehaene, E. Spelke, Trends Cognit. Sci. 8, 307 (2004).

7. P. Bloom, How Children Learn the Meanings of Words (MIT Press, Cambridge, MA, 2000)

8. H. Wiese, Numbers, Language, and the Human Mind (Cambridge Univ. Press, Cambridge, 2003).

9. K. Wynn, Cognition 36, 155 (1990).

10. S. Carey, Science 282, 641 (1998).

11. E. Spelke, S. Tsivkin, in Language Acquisition and Conceptual Development, M. Bowerman, S. C. Levinson, Eds. (Cambridge Univ. Press, Cambridge, 2001), pp. 70-100.

12. S. Dehaene, E. Spelke, P. Pinel, R. Stanescu, S. Tsivkin, Science 284, 970 (1999).

13. K. Wynn, Nature 358, 749 (1992).
14. G. M. Sulkowski, M. D. Hauser, Cognition 79, 239 (2001).

15. A. Nieder, E. K. Miller, Proc. Natl. Acad. Sci. U.S.A 101, 7457 (2004).

16. E. M. Brannon, H. S. Terrace, J. Exp. Psychol. Anim. Behav. Processes 26, 31 (2000).

17. E. S. Spelke, S. Tsivkin, Cognition 78, 45 (2001).

18. C. Lemer, S. Dehaene, E. Spelke, L. Cohen, Neuropsychologia 41, 1942 (2003).

19. S. Dehaene, L. Cohen, Neuropsychologia 29, 1045 (1991).

20. H. Barth, N. Kanwisher, E. Spelke, Cognition 86, 201 (2003).

21. J. Whalen, C. R. Gallistel, R. Gelman, Psychol. Sci. 10 130 (1999).

22. B. Butterworth, The Mathematical Brain (Macmillan, London, 1999).

23. P. Gordon, Science 306, 496 (2004); published online 19 August 2004 (10.1126/science.1094492).

24. C. Strömer, Die sprache der Mundurukú (Verlag der Internationalen Zeitschrift "Anthropos," Vienna, 1932).

25. M. Crofts, Aspectos da língua Mundurukú (Summer Institute of Linguistics, Brasilia, 1985).

26. See supporting data on Science Online.

27. T. Pollmann, C. Jansen, Cognition 59, 219 (1996).

28. R. S. Moyer, T. K. Landauer, Nature 215, 1519 (1967)

29. P. B. Buckley, C. B. Gillman, J. Exp. Psychol. 103 1131 (1974)

30. Comparison performance remained far above chance in two independent sets of trials where the two sets were equalized either on intensive parameters (such as dot size) or on extensive parameters (such as total luminance) [see (26)]. Thus, subjects did not base their responses on a single non-numerical parameter. Performance was, however, worse for extensivematched pairs $(88.3 \%$ versus $76.3 \%$ correct, $P<$ $0.0001)$. We do not know the origins of this effect but it is likely that, like Western subjects, the Mundurukú estimate number via some simple relation such as the total occupied screen area divided by the average space around the items, which can be subject to various biases [see (32)].

31. Performance remained above chance for both intensivematched and extensive-matched sets ( 89.5 and $81.8 \%$ correct, respectively; both $P<0.0001)$. Although the difference between stimulus sets was again significant $(P<0.0001)$, it was identical in Mundurukú and French subjects. Furthermore, performance was significantly above chance for a vast majority of items (44/51) and was never significantly below chance, making it unlikely that participants were using a simple shortcut other than mental addition. For instance, they did not merely compare $n 1$ with $\mathrm{n} 3$ or $\mathrm{n} 2$ with $\mathrm{n} 3$, because when $\mathrm{n} 1$ and $\mathrm{n} 2$ were both smaller than $n 3$, they still discerned accurately whether their sum was larger or smaller than the proposed number $n 3$, even when both differed by only $30 \%$ (76.3 and $67.4 \%$ correct, respectively; both $P<0.005)$.

32. J. Allik, T. Tuulmets, Percept. Psychophys. 49, 303 (1991).

33. This work was developed as part of a larger project on the nature of quantification and functional categories developed jointly with the linguistic section of the Department of Anthropology of the National Museum of Rio de Janeiro and the Unité Mixte de Recherche 7023 of the CNRS, with the agreement of Fundação Nacional do Índio (FUNAI) and Conselho Nacional de Desenvolvimento Científico e Tecnológico (CNPQ) of Brazil. It was supported by INSERM, CNRS, the French Ministry of Foreign Affairs (P.P.), and a McDonnell Foundation centennial fellowship (S.D.). We thank E. Spelke and M. Piazza for discussions, A. Ramos for constant advice, and V. Poxõ, C. Tawé, and F. de Assis for help in testing. Movies illustrating the difficulty of counting for the Mundurukú can be viewed at http://video.rap.prd.fr/ videotheques/cnrs/grci.html.

Supporting Online Material

www.sciencemag.org/cgi/content/full/306/5695/499/ DC1

Materials and Methods

References

Documentary Photos

Movie S1

28 June 2004; accepted 3 September 2004

\title{
Samuel M. McClure, ${ }^{1 *}$ David I. Laibson, ${ }^{2}$ George Loewenstein, ${ }^{3}$ Jonathan D. Cohen ${ }^{1,4}$
}

\begin{abstract}
When humans are offered the choice between rewards available at different points in time, the relative values of the options are discounted according to their expected delays until delivery. Using functional magnetic resonance imaging, we examined the neural correlates of time discounting while subjects made a series of choices between monetary reward options that varied by delay to delivery. We demonstrate that two separate systems are involved in such decisions. Parts of the limbic system associated with the midbrain dopamine system, including paralimbic cortex, are preferentially activated by decisions involving immediately available rewards. In contrast, regions of the lateral prefrontal cortex and posterior parietal cortex are engaged uniformly by intertemporal choices irrespective of delay. Furthermore, the relative engagement of the two systems is directly associated with subjects' choices, with greater relative fronto-parietal activity when subjects choose longer term options.
\end{abstract}

In Aesop's classic fable, the ant and the grasshopper are used to illustrate two familiar, but disparate, approaches to human inter- temporal decision making. The grasshopper luxuriates during a warm summer day, inattentive to the future. The ant, in contrast, 